\title{
PIBID, EDUCAÇÃO FÍSICA E FORMAÇÃO DOCENTE: UM ESTADO DA ARTE DAS PRODUÇÕES NACIONAIS
}

Ségio Luiz Gibim dos Santos, Márcia Regina Canhoto de Lima; José Milton de Lima; Jéssica Kurak Ponciano.

Universidade Estadual Paulista - UNESP, Curso de Educação Física, Presidente Prudente, SP. E-mail: sergiogibim.89@gmail.com.

\section{RESUMO}

Este artigo compõe uma síntese da pesquisa desenvolvida durante o segundo semestre do ano de 2017, empreendida na FCT - UNESP Presidente Prudente e teve como objetivo realizar uma análise de caráter qualitativo e quantitativo sobre toda a produção científica brasileira publicada em periódicos científicos nacionais que contemple, de modo integrado, discussões sobre formação de professores, PIBID e Educação Física. Para a realização desta investigação, procedemos com o método de investigação denominado "estado da arte", analisando variadas bases de dados que compilam artigos científicos. Após a coleta dos dados, a pesquisa buscou contribuir com a produção do conhecimento acerca desta temática a fim de identificar as fragilidades e as potencialidades do PIBID enquanto política pública que atua diretamente na formação de professores e no processo de construção da identidade docente. Concluiu-se, ao final da pesquisa, que muitos foram os trabalhos que trouxeram o PIBID como um elemento que contribui tanto em termos sociais, quanto em termos acadêmicos no processo de subjetivação profissional dos licenciados do curso de Educação Física.

Palavras-Chave: PIBID; Educação Física; Estado da Arte; Formação Docente; Pesquisa Bibliográfica.

\section{PIBID, PHYSICAL EDUCATION AND TEACHER TRAINING: A STATE OF THE ART OF NATIONAL PRODUCTIONS}

\begin{abstract}
This article composes a synthesis of the research developed during the second semester of 2017, undertaken at FCT - UNESP Presidente Prudente and had as objective to carry out a qualitative and quantitative analysis on all the Brazilian scientific production that contemplate, in an integrated way, discussions on teacher training, PIBID and Physical Education. To carry out this research, we proceeded with the research method called "state of the art", analyzing various databases that compose scientific articles. After the data collection, the research sought to contribute to the production of knowledge about this theme to identify the weaknesses and potentialities of the PIBID as a public policy that acts directly in teacher training and in the process of constructing the teaching identity. It was concluded, at the end of the research, that many of the works that brought the PIBID as an element that contributed both socially and academically in the process of professional subjectification of the graduates of the Physical Education course.
\end{abstract}

Keywords: PIBID; Physical Education; State of art; Teacher Training; Bibliographic research. 


\section{INTRODUÇÃO}

O PIBID - Programa Institucional de Bolsas de Iniciação à Docência - é uma política pública educacional com edital lançado em dezembro de 2007 pelo então Ministro da Educação Fernando Haddad e pela Coordenação de Aperfeiçoamento de Pessoal de Nível Superior (CAPES), que visa aprimorar o processo de formação de professores para a educação básica a partir de um intercâmbio entre Instituições de Ensino Superior (IES) e Escolas de Educação Básica, onde o estudante matriculado na primeira metade do curso de licenciatura é inserido no cotidiano escolar em paralelo com as atividades na Universidade sendo acompanhado por professores das duas instituições, contribuindo com o processo de formação inicial de professores. Para Felício (2014, p. 419) "O PIBID se institui como uma possibilidade de articulação entre a teoria e a prática ao longo do processo de formação inicial", fato este, que contribui para a valorização das licenciaturas do país.

Para tanto, o PIBID conta com uma equipe formada por professores supervisores, coordenadores de área e coordenador institucional. Segundo o Edital № 7/2018 o Coordenador Institucional (Cl) tem como função mediar as ações da CAPES, as Instituições de Ensino Superior (IES) e outros integrantes. Os professores Coordenadores de Área (CA) são responsáveis pelo desenvolvimento do subprojeto e da orientação dos alunos na IES, enquanto o Professor Supervisor (PS) tem como função acompanhar os alunos nas escolas públicas de educação básica. Considera-se o aluno na primeira metade do curso, aquele que cumpriu menos de $60 \%$ da carga horária total do curso (BRASIL, 2018).

Lima et al (2014) dizem que a formação inicial de professores tem como objetivo formar profissionais preparados para lidar com as dificuldades do cotidiano escolar e exercer a docência de maneira que relacione o contexto histórico cultural do aluno com suas práticas pedagógicas, visando a formação de um cidadão crítico e reflexivo. O processo formativo nos cursos de licenciatura sofre com a precariedade estatal, com o sucateamento da universidade pública, e outros fatores exógenos, esta condição interfere de forma direta na formação dos discentes e futuros professores. Desta forma, um processo de formação contingente, pode contribuir também para a desvalorização profissional que afeta continuamente a docência brasileira.

Por esta razão, a presente pesquisa buscou empreender uma análise quantitativa e qualitativa, que segundo Fonseca (2002), "permite recolher mais informações do que se poderia conseguir isoladamente" (p. 20), de artigos publicados de $07 / 2013$ a 07/2018, que versam sobre as experiências ou percepções de pesquisadores ligados à subprojetos PIBID Educação Física em todo território nacional. A pesquisa qualitativa considera que a realidade só é compreendida se baseada na análise de dados brutos, recolhidos com instrumentos padronizados (FONSECA, 2002). Ademais, enfatiza o subjetivo como meio de compreender e interpretar as experiências, e analisa as informações narradas de uma forma organizada, mas intuitiva (POLIT, 2004).

\section{METODOLOGIA}

Utilizamos a técnica de análise denominada "estado da arte" para procedermos a nossa investigação. Compreendemos, dessa forma que o "estado da arte" representam uma contribuição fundamental na constituição do campo teórico de uma determinada área de conhecimento, e objetivam identificar os aportes mais relevantes da construção da teoria e/ou prática pedagógica, indicam as restrições sobre o campo em que debruça a investigação, as suas lacunas de divulgação, tencionam revelar também as experiências inovadoras investigadas que indiquem alternativas de solução para os problemas da prática, trabalhando no processo de reconhecimento das contribuições da pesquisa na constituição da propostas na área evidenciada (ROMANOWSKI; ENS, 2006, p. 39).

Para Minayo (2001), a pesquisa qualitativa trabalha com o universo de significados, motivos, aspirações, crenças, valores e atitudes, o que corresponde a um espaço mais profundo 
das relações, dos processos e dos fenômenos que não podem ser reduzidos à operacionalização de variáveis. Neste sentido, a pesquisa bibliográfica, segundo Fonseca (2002):

[...] é feita a partir do levantamento de referências teóricas já analisadas, e publicadas por meios escritos e eletrônicos, como livros, artigos científicos, páginas de web sites. Qualquer trabalho científico inicia-se com uma pesquisa bibliográfica, que permite ao pesquisador conhecer o que já se estudou sobre o assunto. Existem, porém pesquisas científicas que se baseiam unicamente na pesquisa bibliográfica, procurando referências teóricas publicadas com o objetivo de recolher informações ou conhecimentos prévios sobre o problema a respeito do qual se procura a resposta $(2002$, p. 32).

Fonseca (2002) lembra ainda que as conclusões não devem ser apenas um resumo dos trabalhos. Mas, devemos ter cuidado ao selecionar e analisar as pesquisas de maneira que não comprometa a qualidade da mesma com erros de coleta ou análise (FONSECA, 2002). Por intermédio de uma busca feita na internet em julho de 2018, fizemos um levantamento de artigos produzidos no Brasil entre os anos de 2013 e 2018. Para tanto, foram utilizados os seguintes bancos de dados: Periódicos CAPES, Sibi USP, Parthenon UNESP e Portal e Periódicos Eletrônicos Científicos (PPEC) Unicamp. Na busca utilizamos os seguintes descritores em português: PIBID e Educação Física; e os seguintes descritos em inglês: PIBID e Physical Education. Desta maneira, foram encontrados 246 trabalhos e, em seguida, buscando refinar os resultados aplicou-se o critério periódicos revisados por pares, restaram apenas 192 produções. Por fim, foi realizada a leitura dos títulos e resumos, nesta etapa foram eliminados os trabalhos duplicados, restando apenas 9 obras que se relacionam com o tema proposto de acordo com o fluxograma:

Figura 1. Fluxograma para inclusão de trabalhos.

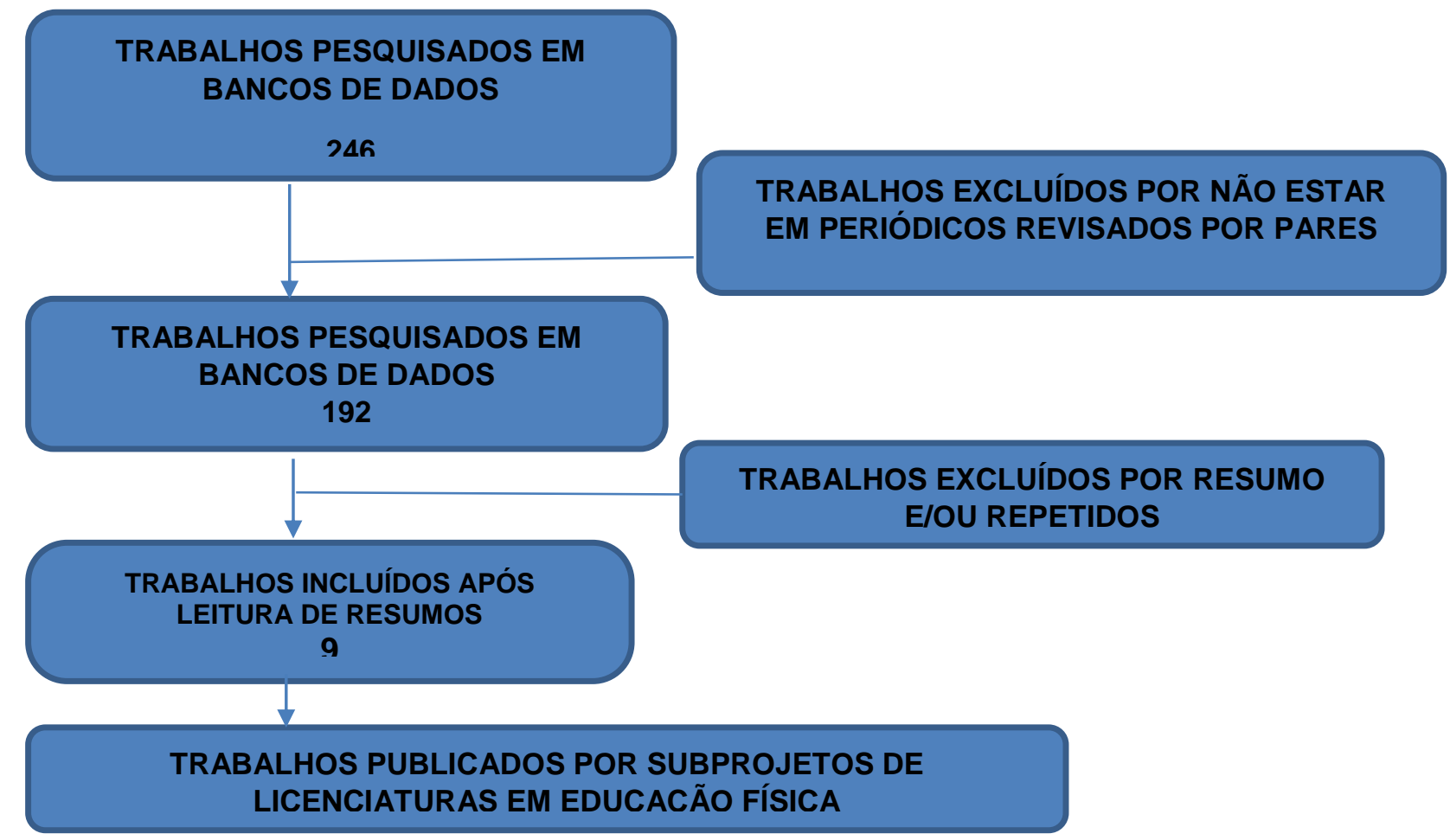

Fonte: Autores. 


\section{RESULTADOS E DISCUSSÃO}

Percebemos uma maior concentração de produções científicas no Estado do Rio Grande do Sul (5), seguido por São Paulo, Goiás, Mato Grosso do Sul e Mato Grosso. Os demais Estados em conjunto com o Distrito Federal, não obtiveram trabalhos encontrados nessa pesquisa, o que não significa que não existam publicações. Dentre as Universidades, a Federal de Santa Maria foi a que mais publicou (4), seguidas da UNESP, as Universidades Federais de Goiás, Mato Grosso e Mato Grosso do Sul com 1 trabalho publicado. A única universidade particular presente na pesquisa é a Universidade da Cruz Alta (RS), também com uma publicação.

Ao comparar a frequência de publicações ao longo dos anos, podemos perceber que houve um salto de 2013 para 2014. Este crescimento pode ser pelo fato de os subprojetos já terem algum tempo engajados em suas atividades e por consequência, conseguir obter resultados significativos para publicar. A partir de então, ocorre uma queda no número de produções, talvez pela incerteza de continuidade do PIBID que, ano a ano sofreu com possibilidade de corte ou extinção, o que pode ter desestimulado pesquisadoras e pesquisadores desenvolver pesquisa sobre a temática.

Para compreender melhor os dados gerados a partir das buscas nas bases de dados, organizamos os resultados em duas categorias de análise. A primeira diz respeito ao impacto do PIBID na formação inicial de professores, com 4 trabalhos. A segunda trata dos relatos de atividades realizadas durante as intervenções no ambiente escolar, com 5 trabalhos.

\section{IMPACTO DO PIBID NA FORMAÇÃO INICIAL DE PROFESSORES}

O estudo de Welter e Sawitzki (2014) teve como finalidade analisar as implicações do subprojeto PIBID/EDF para a formação inicial em Educação Física. A investigação pretendeu identificar as lacunas evidenciadas pelos bolsistas, no processo de formação docente, a partir das vivências oportunizadas pelo programa iniciação à docência. A pesquisa buscou averiguar como se deu a inserção profissional dos bolsistas nas escolas e identificar as contribuições deste subprojeto para a formação inicial em Educação Física. Nessa análise, observou-se o PIBID como um programa que veio acrescentar para a formação de professores. Para tanto, como procedimento metodológico foi utilizada a pesquisa documental, sistematizada por meio da análise de 44 memoriais descritivos individuais de 22 bolsistas do subprojeto PIBID/EDF no período que compreendeu o primeiro e segundo semestre no ano de 2012, na busca de destacar aspectos relevantes a formação inicial e inserção profissional através das experiências de iniciação à docência pelo subprojeto. No entanto, ainda são poucos aqueles estudantes que conseguem inserir neste espaço e vivenciar experiências profissionais ainda em sua formação inicial.

O artigo que trata da repercussão do PIBID no processo de formação inicial de professores, buscou compreender de que modo as experiências acumuladas no PIBID Subprojeto - "Cultura esportiva da escola" ao longo do período de formação acadêmica na graduação repercutiram sobre o percurso formativo dos alunos egressos do Centro de Educação Física e Desportos da Universidade Federal de Santa Maria CEFD/UFSM. Os relatos apresentados, em sua maioria, identificaram o PIBID como um aporte para a constituição da identidade profissional no decorrer do percurso formativo, trazendo a afirmação na profissão e o amadurecimento do acadêmico, ainda que essa identidade se configure de forma provisória e inacabada, próxima de um processo identitário que se prolongará durante o percurso profissional (CLATES; GÜNTHER, 2015).

Lima et al (2016) tiveram como objetivo investigar e aprimorar o processo de formação inicial de alunos do Curso de Licenciatura em Educação Física da FCT/UNESP de Presidente Prudente e contínua dos profissionais da escola parceira, por meio do processo de estudo, intervenção e reflexão. Analisados os dos dados coletados, aponta-se a importância do PIBID na formação dos licenciados, todavia, o processo pode ser aprimorado com o aprofundamento teórico, a problematização de concepções e a opção consciente de novas atitudes. Através dos 
supervisores, a pesquisa demonstra que a presença dos bolsistas os motiva a aprimorar e a diversificar o seu trabalho, além disso, incentivam os futuros professores a levantar novos conteúdos que enriquecem a prática educativa, aprimorando a educação oferecida nas escolas parceiras.

O estudo de Doarth e Lima (2014) buscou conhecer, descrever e analisar a influência do PIBID na formação de professores de Educação Física escolar, sob o ponto de vista de cinco graduandos de Licenciatura em Educação Física. Os autores concluíram que embora a formação dos professores de Educação Física revele um contexto de exclusão, classificação e seleção da sociedade, as respostas dos acadêmicos do PIBID/UFGD, parecem ter instrumentalizado propostas de transformações desta realidade.

Welter e Sawitzki (2014), Doarth e Lima (2014) e Lima et al (2016), ao analisar documentos produzidos pelos graduandos, ou os próprios bolsistas de iniciação à docência, voltaram seus olhares para o processo de formação de professores de Educação Física para a Educação Básica e buscaram se alinhar com o conhecimento científico mais atual da área para superar modelos autoritários, reducionistas e tecnicistas, e contribuir também, para superar um modelo hierárquico de formação de professores e coloca em pé de igualdade nesse processo a Universidade e a Escola.

Na mesma perspectiva, Clates e Günther (2015) entrevistaram alunos egressos do PIBID que trazem a luz o fato de o Programa também propiciar uma aproximação teórico prática, possibilidade que não é percebida pelos egressos quando se referem à grade curricular comum, relatando a distância das matérias de cunho teórico e os estágios supervisionados, fato que é percebido por Taffarel (2010), que na formação inicial existem algumas lacunas que resultam da dicotomia entre bacharelado e licenciatura; universidade e escola e da desarticulação entre teoria e prática. Dentre os pontos apontados nas produções, os subprojetos Educação Física apresentam importância significativa no processo de formação dos licenciandos ao integrar a teoria e prática como um terceiro espaço de formação profissional, como sugere Felício (2014).

\section{RELATOS DE ATIVIDADES REALIZADAS}

Ao avaliar os dados pré-intervenção, e o diário de campo, Campos, Grunennvaldt e Coffani (2014), entenderam que a "Educação Física dessa escola se mostra como uma atividade carecendo de maior sistematização de seus conteúdos, metodologia e conhecimentos, se mostrando uma aula ausente de uma intencionalidade pedagógica" (p. 33), onde boa parte dos alunos praticavam futsal revezando entre si de acordo com regras estabelecidas por eles próprios, e a outra parte apenas observava: "no pós-questionário suas respostas, movidos pelas vivências proporcionadas pelas aulas aplicadas pelo subprojeto, foram enriquecidas dando vazão a uma margem maior de possibilidades para o tratamento e entendimento do conteúdo esporte, inclusa sua transformação pela escola". (CAMPOS; GRUNENNVALDT; COFFANI, 2014, p. 33)

Ferreira et al (2015), Fanchi (2013) e Klein (2014) concordam, em seus relatos, que a Educação Física Escolar nas instituições parceiras de seus respectivos subprojetos eram espotivizadas, reforçando o estereótipo de que a área é "apenas um suporte para atividades esportivas" (SANTIN, 1987, p. 46). Neste sentido, os autores reconhecendo a importância das Culturas Corporais de Movimento, trouxeram diferentes práticas corporais, mas reconhecendo que cada uma delas não é mais importante que os demais conteúdos, e sim, maneiras de trabalhar o conteúdo.

Ferreira et al (2015), tiveram como objetivo dar a oportunizar aos alunos o contato com a Ginástica Geral de maneira que possam compreendê-la como fenômeno social e historicamente produzido pelo homem, sendo, portanto, um elemento da cultura corporal de movimento.

Fanchi (2013), parte do princípio que a Educação Física Escolar tem dado prioridade ao esporte, deixando de lado as demais manifestações da Cultura Corporal de Movimento. Propõe 
então, uma intervenção baseada em jogos tradicionais a fim de agregar novas vivências nas aulas da escola. Para as atividades, os alunos fizeram pesquisas com familiares perguntando quais jogos e brincadeiras seus pais e avós faziam quando criança. Por tanto, os alunos fizeram parte do processo de planejamento das atividades de maneira que o conteúdo tivesse mais significado.

Klein (2014) tem como objetivo estabelecer metodologias de ensino do futsal como um meio para a formação do ser humano nas perspectivas cognitivas, afetivas e sociais. O Autor apresenta vários métodos de ensino esportivo e destaca que o modelo a ser escolhido deve ser de acordo com cada grupo a ser trabalhado. Lembra ainda que um método pode ser substituído por outro conforme a evolução da turma.

Panda e Puglia (2016) avaliaram a aptidão física relacionada à saúde e ao desempenho esportivo dos escolares diagnosticados com deficiência Intelectual leve, de três escolas participantes do Programa Institucional de Bolsa de Iniciação à Docência PIBID/UNICRUZ/Educação Física. Os resultados mostram que a maioria dos alunos estão com sobrepeso ou obesos de acordo com o Índice de Massa Corporal, e também apresentam baixa flexibilidade.

Na categoria relatos de experiência, os autores Franchi (2013), Ferreira et al. (2015) e Campos, Grunennvaldt e Coffani (2014), percebem que a falta de sistematização de conteúdos leva à simples esportivização do conteúdo, fato que contribui para a desvalorização da Educação Física Escolar. E a fim de valorizar e desenvolver os elementos da Cultura Corporal de Movimento, sugerem práticas pedagógicas de maneira que os alunos possam compreender o conteúdo como fenômenos sociais construídos historicamente pelo homem. Já Klein (2014), apresenta uma metodologia tecnicista para o ensino do futsal, contrapondo em alguns aspectos a tendência das produções da área.

\section{CONCLUSÃO}

Por fim, concluímos que o PIBID contribui de maneira qualitativa para o processo de formação de professores, entretanto, os autores concordam que o acesso ao programa é restrito a poucos graduandos e sugerem que este é o melhor modelo para o estágio de docência durante a graduação. Sugerimos ainda, mais pesquisas sobre a temática com o intuito de elucidar as lacunas encontradas no processo formativo das licenciaturas em Educação Física. Além disso, observamos que, em virtude do êxito obtido pelo PIBID, este deveria figurar como um modelo efetivo de estágio, fato que não ocorre, visto que uma parcela muito pequena dos alunos de graduação tem acesso à esta política pública. As pesquisas encontradas, em decorrência do número e da abordagem que realizam, mostram uma deficiência de produções que investiguem a efetividade de PIBID no curso de licenciatura em Educação Física.

Outro importante dado, encontrado na maioria das investigações sobre a percepção das aulas de Educação Física pelos alunos beneficiários do PIBID diz respeito à excessiva abordagem da esportivização nas aulas, o que contribui para o desprestígio da disciplina por parte dos alunos da educação básica. Ao observarem estes aspectos, os graduandos serão capazes de ressignificar os seus processos formativos, incorporando futuramente, em sua prática docente, mais atividades voltadas para a Cultura Corporal de Movimento como um todo. Esperamos que pesquisas como este escopo tragam maiores possibilidades de discussão acerca de estratégias que possam figurar, de maneira efetiva, na construção de estágios para os cursos de licenciatura em Educação Física transformadores e significativos para os futuros docentes. 


\section{REFERÊNCIAS:}

CAMPOS, Jéssika Ribeiro da Costa; GRUNENNVALDT, José Tarcísio; COFFANI, Marcia Cristina Rodrigues da Silva. Educação física e ensino médio: da regulação instituída para a construção permanente da experiência. Conexões, Campinas, SP, v. 12, n. 2, p. 13-36, jul. 2014. https://doi.org/10.20396/conex.v12i2.2166.

FELÍ́CIO, H. M. dos S. O PIBID como "terceiro espaço" de formação de professores. Rev. Diálogo Educ., Curitiba, v. 14, n. 42, p. 415-434, maio/ago. 2014.

FERREIRA, Andreia Cristina Peixoto et al. A ginástica geral na intervenção do PIBID de educação física numa perspectiva de formação cultural e inclusão social. Conexões, Campinas, SP, v. 13, p. 126, maio 2015.

FONSECA, João José Saraiva. Metodologia da Pesquisa Científica. 2002.

FRANCHI, Silvester. Jogos tradicionais/populares como conteúdo da cultura corporal na Educação Física escolar. Motrivivência, Florianópolis, n. 40, p. 168-177, jul. 2013. ISSN 2175-8042.

KLEIN, Rafael Rodrigo. Métodos de ensino para o futsal escolar. Conexões, Campinas, SP, v. 12, n. 4, p. 91-96, dez. 2014. ISSN 1983-9030.

PANDA, Maria Denise Justo; PUGLIA, Marilia Basilio. Aptidão física de escolares com deficiência intetectual leve. Cinergis, Santa Cruz do Sul, v. 17, n. 2, ago. 2016.

POLIT, D. F.; BECK, C. T.; HUNGLER, B. P. Fundamentos de pesquisa em enfermagem: métodos, avaliação e utilização. Trad. de Ana Thorell. 5. ed. Porto Alegre: Artmed, 2004.

ROMANOWSKI, Joana Paulin; ENS, Romilda Teodora. As pesquisas denominadas do tipo" Estado da Arte. Revista Diálogo Educacional, v. 6, n. 19, 2006.

SANTIN, S. Educação Física: uma abordagem filosófica da corporeidade. ljuí: Unijuí, 1987.

TAFFAREL, C. Do trabalho em geral ao trabalho pedagógico: Contribuição ao debate sobre o trabalho pedagógico na Educação Física. Motrivivência, Santa Catarina, Ano XXII, $\mathrm{n}^{\circ}$. 35, dezembro/2010.

WELTER, Jaqueline; SAWITZKI, Rosalvo Luis. As implicações do subprojeto cultura esportiva da escola-PIBID/EDF para a formação inicial em educação física. Motrivivência, Florianópolis, v. 26, n. 43, p. 262-276, nov. 2014. https://doi.org/10.5007/2175-8042.2014v26n43p262. 